University of Wollongong

Research Online

Faculty of Engineering and Information

Faculty of Engineering and Information

Sciences - Papers: Part A

Sciences

2012

Teaching Monte Carlo codes at university: Development of a Geant4 course for students of schools of physics

Susanna Guatelli

University of Wollongong, susanna@uow.edu.au

Dean Cutajar

University of Wollongong, deanc@uow.edu.au

Anatoly B. Rosenfeld

University of Wollongong, anatoly@uow.edu.au

Catherine Layton

University of Wollongong, cathlay@uow.edu.au

Follow this and additional works at: https://ro.uow.edu.au/eispapers

Part of the Engineering Commons, and the Science and Technology Studies Commons

Research Online is the open access institutional repository for the University of Wollongong. For further information contact the UOW Library: research-pubs@uow.edu.au 


\title{
Teaching Monte Carlo codes at university: Development of a Geant4 course for students of schools of physics
}

\author{
Abstract \\ Nowadays, it is important that students of Schools of Physics include the study of Monte Carlo codes in \\ their curriculum as these codes are widely used in research. At the School of Engineering Physics of the \\ University of Wollongong, we designed and set in place a Geant 4 course addressed to the Medical \\ Physics domain. In this paper, we illustrate the main features of the course and its development since \\ 2010. The design of this course maybe adopted to teach Geant 4 or any other Monte Carlo code, and in \\ general to teach complex software tools to students with limited computing background. @ 2012 IEEE.

\section{Keywords} \\ schools, physics, university, codes, carlo, development, monte, geant4, teaching, course, students

\section{Disciplines} \\ Engineering | Science and Technology Studies

\section{Publication Details} \\ Guatelli, S., Cutajar, D., Rosenfeld, A. B. \& Layton, C. (2012). Teaching Monte Carlo codes at university: \\ Development of a Geant4 course for students of schools of physics. Proceedings of IEEE International \\ Conference on Teaching, Assessment, and Learning for Engineering, TALE 2012 (pp. W2C-11-W2C-15). \\ Australia: IEEE.
}




\section{Teaching Monte Carlo Codes at University: Development of a Geant4 Course for Students of Schools of Physics}

\author{
Susanna Guatelli, Dean Cutajar, Anatoly B. Rosenfeld \\ Centre For Medical Radiation Physics \\ University of Wollongong \\ Wollongong, Australia
}

\author{
Catherine Layton \\ Centre for Educational Development, Innovation \\ and Recognition \\ University of Wollongong \\ Wollongong, Australia
}

\begin{abstract}
Nowadays, it is important that students of Schools of Physics include the study of Monte Carlo codes in their curriculum as these codes are widely used in research. At the School of Engineering Physics of the University of Wollongong, we designed and set in place a Geant 4 course addressed to the Medical Physics domain. In this paper, we illustrate the main features of the course and its development since 2010. The design of this course maybe adopted to teach Geant4 or any other Monte Carlo code, and in general to teach complex software tools to students with limited computing background.
\end{abstract}

Index Terms-learning-teaching-research nexus; undergraduate; postgraduate; problem-based learning; Monte Carlo code; Geant 4

\section{INTRODUCTION}

Nowadays it is important to include the teaching of Monte Carlo codes in the curriculum of undergraduate and postgraduate students of Schools of Physics. This is due to the intensive use of Monte Carlo codes in radiation physics research, spanning from solid state physics and High Energy Physics to space science and medical physics. Monte Carlo codes are also extensively used in medical physics centers of hospitals to verify treatment planning.

Geant4 [1], [2] is a widely used Monte Carlo code describing the passage of particles through matter, which is developed, maintained, and upgraded through an international collaboration (the Geant4 Collaboration).

The use of Geant4 is taught to practitioners and researchers by the Geant 4 Collaboration, but the teaching of scientific computing tools for undergraduates is usually delegated to research centers, where students work on their Honours/Masters theses.

At the University of Wollongong, over the last two years, teaching staff of the School of Engineering Physics and of the Centre For Medical Radiation Physics (CMRP) have been experimenting with extending the reach of Geant 4 into the undergraduate/postgraduate curriculum to: enhance the learning-teaching-research nexus [3]; teach more efficiently; remedy gaps in the curriculum as they became apparent; and better support students in grasping the potential of Geant 4 as Monte Carlo code for medical physics.

In our context, Geant 4 is used to verify radiotherapy treatment planning, to design novel detectors, and to study novel radiotherapy treatments.

The full list of publications based on the use of Geant 4 at CMRP can be found in [4].

At CMRP, approximately $40 \quad$ students (Masters/Honours/PhD) each year work on their thesis project, with approximately one third of them using Geant 4 as the simulation tool in their research. In our School, the need to design and set in place a course to teach Geant 4 efficiently to undergraduate and postgraduate students alike became of primary importance.

In this paper, we briefly describe the changes made to the course since 2010, the problems we have faced, and the impacts on students' achievement of intended learning outcomes. We go on to delineate the approach we are now developing. Grounded in problem-based learning (PBL) theory and processes, we anticipate that our new approach, which blends online independent study with existing collaborative workshop processes, will more effectively address students' learning needs and simultaneously build both independent and collaborative research skills.

Given the widespread use of Geant4, this project is of general interest; many Schools of Physics may profit from our experience in designing this integrated, problem-based Geant4 course. The same course design maybe adopted to teach other Monte Carlo codes, and in general to teach complex software tools to students with poor computing background.

\section{The GEANT4 Course: The First DESIGN AND ITS EVOLUTION}

In 2010, we designed a hands-on Geant 4 course addressed to undergraduate/postgraduate students, based on previous experience in Geant4 courses organized by the Geant4 Collaboration [5]. We hoped to draw lecturers, tutors, postgraduate and undergraduate students together, and bridge perceived teaching-research and postgraduate-undergraduate 
Session W2C

divides by developing a community of practice [6]. It has been established that most learning in communities of practice (usually through apprenticeships) do not merely involve a topdown relationship between the student and the master, but are embedded in a practice-centered community that acts as a living curriculum for everyone in that community, where listening to practice-related conversations is an integral part of the learning experience [7], [8]. Learning and improvements in practice are facilitated by visual and auditory access to the activities of other learners and experts - talk is embedded in action and action is embedded in talk.

The course we developed in this first iteration is fully described in [9], [10]. The students had to develop a dosimetric system for brachytherapy through a series of exercises in three laboratory sessions. The course consisted of practical computing sessions interlaced with theoretical seminars. The students were provided with laptops and they used the computing resources of CMRP to develop, test and execute the Geant4 simulations they were developing in postgraduate/undergraduate pairs. They were supported in their learning process by two lecturers and three tutors (one tutor for approximately eight students). At the end of the course, the students' understanding was assessed on the basis of a written report. Their feedback, and lecturers' observations, indicated that further changes would be required.

With so many teaching staff present, it was quickly apparent that the primary barrier, at postgraduate and undergraduate levels alike, was students' lack of familiarity with $\mathrm{C}++$ programming language. The students had no awareness of Monte Carlo methods, of Geant4, or of the use of the Linux platform. Few students had a computing science background and they coped well with the Geant4 course.

We also faced a lack of time in the curriculum; twelve hours was insufficient, because of the lack of fundamental prerequisites in the preceding curricula. Postgraduate students were not in a position to draw undergraduate students towards the research community. We concluded that a broad notion of research/learning communities as a framework for enhancing the teaching-research nexus had severe limitations [10]. Perhaps contact with a variety of experts and a less pressurized student-to-student relationship, would have a greater impact?

In 2011, then, over a three-day period, students spent the morning at an international Geant4 User Workshop, in theoretical seminars given by world experts [11], and then undertook Geant4 practical hands-on sessions in the afternoon, in especially constructed groups of three. It was anticipated that the triads would be better able to problem-solve, share a broader information and experience base, coordinate their activities and reflect on what they were doing than had previously been the case. Certainly, students coped more effectively with learning $\mathrm{C}++$ and Geant 4 , but the contact with expert practice proved overwhelming - if anything, students retreated into a learners' community.

A snapshot of the feedback we received about these innovations is provided in Tables I and II, which highlight feedback from students about what they learned in 2010 and
2011 from the hands-on course and the supplementary activities that were provided.

TABLE I. STUDENTS' FEEDBACK ON WORKSHOP (DAY 1)

\begin{tabular}{|l|l|c|c|}
\hline \multirow{5}{*}{} & \multicolumn{3}{|c|}{ Responses } \\
\cline { 2 - 4 } & \multicolumn{1}{|c|}{ Issue } & $\begin{array}{c}\text { Cohort } \\
\mathbf{2 0 1 0} \\
(\mathbf{N = 1 7 )}\end{array}$ & $\begin{array}{c}\text { Cohort } \\
\mathbf{2 0 1 1} \\
(\mathbf{N = 2 2})\end{array}$ \\
\hline \multirow{5}{*}{ Learnt } & $\begin{array}{l}\text { Grasp of radiotherapy } \\
\text { principles }\end{array}$ & 13 & - \\
\cline { 2 - 4 } & $\begin{array}{l}\text { Computing/programming } \\
\text { skills }\end{array}$ & 6 & 20 \\
\hline Not knowing coding & 10 & 17 \\
\cline { 2 - 4 } & $\begin{array}{l}\text { Utterly stumped by C++ } \\
\text { difficulties }\end{array}$ & 10 & - \\
\cline { 2 - 4 } & Need for guidance & 6 & 1 \\
\hline
\end{tabular}

$N$ indicates the number of students of each course providing feedback

TABLE II. StUdents' FEEDBACK ON WORKSHOP (DAY 3)

\begin{tabular}{|c|c|c|c|}
\hline & \multicolumn{3}{|c|}{ Responses } \\
\hline & Issue & $\begin{array}{c}\text { Cohort } \\
2010 \\
(N=15)\end{array}$ & $\begin{array}{c}\text { Cohort } \\
2011 \\
(N=18)\end{array}$ \\
\hline \multirow{2}{*}{$\begin{array}{l}\text { Value of } \\
\text { groupwork }\end{array}$} & $\begin{array}{l}\text { Teamwork and clarifying } \\
\text { ideas and processes }\end{array}$ & 8 & 16 \\
\hline & Self-evaluation & 7 & - \\
\hline \multirow{2}{*}{$\begin{array}{l}\text { Experience of } \\
\text { groupwork }\end{array}$} & Positive & 12 & 13 \\
\hline & Negative & 4 & 1 \\
\hline \multirow{3}{*}{ Difficulties } & No particular difficulties & 4 & 7 \\
\hline & Technical skills & 5 & 8 \\
\hline & Language barriers & 5 & 1 \\
\hline
\end{tabular}

$N$ indicates the number of students of each course providing feedback

It is clear that, in 2011, we had managed to successfully address the programming issues that had utterly stumped the first cohort (Table I). We were also trying to build a bridge between undergraduate and postgraduate students, to foster the teaching-research nexus. Table II illustrates students' views across the two years of the course.

The groupwork component was valued by both cohorts, but the difficulties experienced by students in dealing with the novel material were fewer when the students worked in triads, as compared to pairs.

The next iteration of development of the Geant 4 course we present here attempts to overcome the limitations and problems of these two previous iterations, and enhance students' capacities to engage with Geant4 by specifically addressing coding issues and problem-solving, among other issues described below. At the same time, some of the resources being created will be able to be used at an earlier point in students' studies, and potentially in other courses that depend upon a thorough grasp of $\mathrm{C}++$ programming. 


\section{Session W2C}

\section{The GeAnt4 Course: The TeAching/LEARNing APPROACH}

What we now aim to do is to design the curriculum in such a way that learning how to program $\mathrm{C}++$ and to use Geant 4 is embedded in problems of practice, with in-class problem solving supported by online learning packages. We also aim to recognize that high levels of anxiety can be generated by unfamiliar demands, and that we need to explicitly attend to students' transition into this new field, by providing props and supports that help them engage, "transitional objects" [12].

We are adopting a problem-based learning [13] approach, with some structured learning components.

\section{A. Designing the Curriculum}

First of all a set of objectives which provide guidelines for students in their choice of problems and areas of study needs to be established. In this case, we have already established the central problem - developing a Geant4-based dosimetric system for brachytherapy; any sub-problems that might build toward this main problem have yet to be identified.

The objectives for the subject in which this work is located require students to understand: the Monte Carlo method and why it is used in radiation physics and, in particular, medical radiation physics; why Monte Carlo codes are used to verify radiotherapy treatment planning; and how to use Geant 4 .

In addressing this problem, students need also to employ a range of reasoning skills central to effective practice:

1) identifying what the Geant 4 simulation should do (simulation requirements);

2) identifying the methodology to develop the simulation;

3) implementing the functionality of the simulation, in terms of experimental set-up of the simulation, physics processes to model, selection of simulation parameters (i.e., threshold of production of secondary particles, step length, etc.), output of the simulation;

4) how to verify the correct functionality of the simulation;

5) how to validate the simulation with respect to reference data.

We identified as teaching and learning strategies supporting the development of this scientific research reasoning as being:

- a groupwork-based tutorial process;

- individual study that contributes to understanding and addressing the presenting problem;

- the support of web-based tutorials;

- the presence of tutors supporting the students during the course.

We identified an assessment process as final product that will demonstrate the learning, and support students in their learning.
We provide each student with a laptop with wireless connection to the CMRP cluster. Students may use such laptops during all phases of the course. Three dual cores, 3$\mathrm{GHz}$ computers are sufficient for approximately 25 students. Geant4 and ROOT [14] are installed on each computer and the simulation environment is set-up for each student account. A dummy Geant4 simulation is provided as starting point. A webpage is set-up to guide the students through the entire course.

\section{B. Problem-Based Learning}

In our Geant 4 course we will be adopting a problem-based learning (PBL) approach [13]. This involves students working, in small groups (inside the classroom) and individually (outside the classroom), towards understanding or resolving a problem, with the problem as a starting point for rigorous inquiry. This approach has the strength of building skills integral to expert professional practice, where novel problems that require inquiry and judgment are the norm. Fig. 1 shows the PBL process.

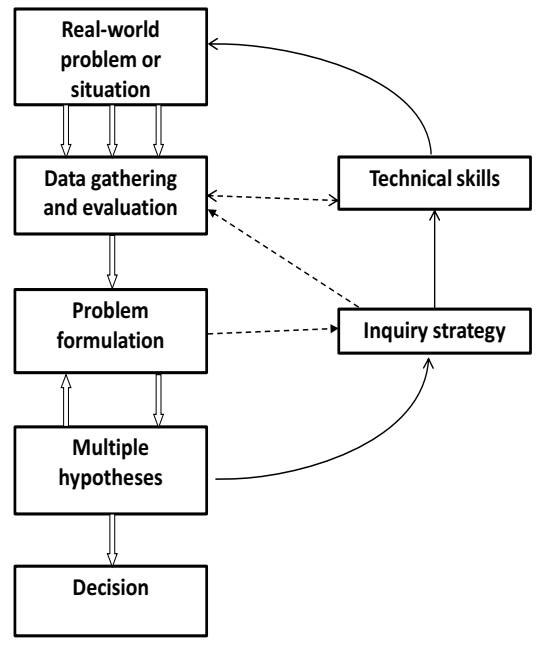

Figure 1. Problem-solving process (adapted from [14, p. 40]).

PBL is based on studies of physician responses to standardized simulated patient encounters, followed immediately by reviewing a recording of the encounter, with the physician explaining what $\mathrm{s} / \mathrm{he}$ was thinking at particular points [15]. Novices (students) learn how to think like experts. Theory and practice are intimately connected.

Skills of inquiry, reasoning and critical evaluation of information, intervention selection and design are built into the learning process, highly supported by tutors at the beginning of a course, but with increasing autonomy once students are familiar with the process. The small group teaching combines the acquisition of knowledge and thinking skills with the development of graduate capabilities such as communication, teamwork and respect for others' views.

PBL emerged in the 1960s, and has been used in engineering since the 1980s; while many claims have been made for the value of the approach (with the lack of a difference in knowledge levels between PBL approaches and didactic approaches, but an increase in skill development, the 


\section{Session W2C}

most common findings), research into its effectiveness is in its infancy [16]. PBL is not a rigid template that can be applied uniformly across time and place - factors that may influence student learning in the particular PBL setting, along with the tools and ongoing coaching that will help students learn and collaborate must be inbuilt [17].

The PBL approach is well suited to our focus on enhancing the learning-teaching-research nexus, as this approach has its foundations in scientific research methodology.

In the next iteration of the Geant 4 course, the problembased approach will be the core of the teaching/learning process. The course will consist of four key stages, summarized below: 1) the preliminary phase; 2) the preparatory phase, 3) the Geant4 hands-on course; and 4) the assessment. Details are provided in Section IV.

\section{The Geant4 Course: The Structure}

\section{A. Preliminary Phase}

The students will develop a personal learning development plan, as a benchmark for study priorities and self-evaluation, and to provide them with a "transitional object" [12], which, because of its' explicit recognition and acceptance of learning gaps, should provide them with a greater sense of control over their learning and reduce their anxieties. The "Learning Development Plan" includes the following sections:

- the Faculty Graduate Qualities;

- the overall course objectives;

- the particular subject objectives;

- the student's knowledge and skills in relation to the subject, whatever their source;

- the student's questions about the subject objectives, processes and content to which they would like to have answers by the end of the session.

On the basis of this analysis, students are able to identify areas of potential weakness in their problem-solving capacities, which they keep in mind as they address each problem - is it with data gathering, generating multiple hypotheses, or technical skills, or what? Then, when they encounter the knowledge gap, they can decide just to note it down for further study, access a nearby resource (a person or text) if it is a minor block, or turn to, and carefully address, the knowledge gap through independent study if it is a major blockage or a key knowledge gap. This phase sets the framework for all subsequent phases, and will be worth $10 \%$ (Part A of the assessment, submitted within the first four weeks).

\section{B. Preparatory Phase}

Students undertake independent study of readings, models and methodologies around the knowledge gaps they have identified. It is anticipated that resources will be needed in relation to the basics of 1) software development; 2) $\mathrm{C}++$ language; 3) use of the Linux platform; 4) Monte Carlo method; 5) Geant4 Monte Carlo Toolkit; and 6) methodology to adopt to develop a Geant4-based simulation. Geared towards learning and experimentation, this part will be undertaken independently by students, supported by the webbased interactive materials, and by consultation with lecturers of the course - processes typical of research-related enquiries.

The aim of this phase is to help the students feel certain they have the background knowledge necessary for the Geant4 hands-on course and to foster self-reliance. The students will be able to assess their knowledge by means of a web-based self-assessment form; their understanding of, for example, the unfamiliar terms they have encountered, can be explored in the Geant4 hands-on course.

If the next iteration of the project will show that this phase is not effective, we will consider setting attendance at a basic computing science subject as a requirement for the course.

\section{The Geant4 Hands-On Course}

The course starts with an initial tutorial that builds group cohesion, and sets in train the problem-solving processes the students will use for the subject as a whole. The group of students works, in the face-to-face context, with a facilitator; in the online environment, for certain activities, the facilitator becomes a moderator.

As noted earlier, the students are to develop a Geant4based treatment planning for brachytherapy. They will work in groups of three and discuss and decide upon which requirements of the Geant4 application they will need to develop: which experimental setup to adopt in the simulation, the physics processes to model, the output of the simulation, etc., as indicated in Section III(A). In this phase, students will learn the problem decomposition strategy usually adopted in software development. This course will consist of hands-on parts and theoretical seminars as illustrated in [9]. We will setup a web-based feedback mechanism to provide students with immediate information, in a realistic form, regarding the results of their actions.

\section{The Assessment}

The assessment will be in three parts. Part A is the aforementioned "Learning Development Plan" (worth 10\%). Part B (worth 15\%) requires the submission of three selfselected self-assessments, as follows. Having studied a particular problem, students will be asked:

- What initial cues should I have noted, and how should I have interpreted them?

- What hypothesis should I have generated?

- Were my problems formulations on the right path?

- What tests or formulae should I have used with the problem, and in what sequence?

- Was the method of addressing the problem appropriate?

- What principles have I identified that will help in working with problems with similar characteristics?

- What new information and skills have I learned? 


\section{Session W2C}

- Can I make a model of the mechanisms and/or processes here that will help as a shortcut in the future?

- How has this affected my learning goals? [15]

Part C (worth $75 \%$ ) requires students to submit a written report concerning the brachytherapy dosimetric system they developed in class.

Evaluation of this third iteration of our course will encompass, as it has before, feedback from students on working collaboratively and teacher assessments of the quality of their work. The new element we will be examining, using the "Learning Development Plan" and the three selfassessments, is how effectively we have helped students become more accepting of the risks of learning something new and potentially difficult, and build their capacity to independently address their learning gaps and develop their research skills. We will also be able to monitor use of the online environment to assess the relevance and value of the resources we provide.

\section{E. The Human Resources and Tools Supporting the Course}

Approximately 25 students participate in the course each year, with the teacher/student ratio being two lecturers in total and one tutor for every eight students. The number of tutors has to date been determined by the fact that the level of students' prior knowledge varied from nil to minimal. With the inclusion of a preliminary and preparatory phase as indicated in Sections $\operatorname{IV}(\mathrm{A})$ and $\operatorname{IV}(\mathrm{B})$, the number of tutors may well be lower, with the bulk of the work going into preparing the new learning materials.

\section{CONCLUSION}

Since 2010, we have been developing and refining a Geant 4 course for undergraduate and postgraduate students of the School of Engineering Physics and Medical Radiation Physics at the University of Wollongong. While two successive iterations of the course have clarified the nature of the difficulties students are having with the material, and have allowed for some successes in enhancing the learningteaching-research nexus and building relationships among undergraduate and postgraduate students, it is clear that these innovations have been insufficient for our purposes.

We believe that our forthcoming innovation, more thoroughly grounded in research-based approaches to professional practice and educational theory, and more keenly focused on building self-confidence and skills, is very promising.
The course we are refining is mainly suited for the Medical Physics domain but it may be arranged also to other fields of research, to enhance learning in Physics more broadly in the second and third years of students' studies.

The design of this course may also be adopted to teach other Monte Carlo codes or, in general, complex software tools typical of scientific disciplines, when students have poor computing background.

\section{REFERENCES}

[1] S. Agostinelli et al., "Geant4 - a simulation toolkit," Nucl. Instrum. \& Methods in Physics Research, Section A, vol. 506, No. 3, pp. 250-303, Jul. 2003.

[2] J. Allison et al., "Geant4 developments and applications," IEEE Trans. Nucl. Sci., vol. 53, pp. 270-278, 2006.

[3] University of Wollongong. (2011). The Learning-Teaching-Research Nexus at UOW [Online]. Available: http://www.uow.edu.au/cedir/nexus/index.html.

[4] Centre For Medical Radiation Physics, University of Wollongong. (2012). Geant4 Publications [Online]. Available: http://cmsprd.uow.edu.au/UOW_Main/eng/phys/cmrp/UOW121078.

[5] Geant4. (2012). [Online] Available: http://www.cern.ch/geant4/.

[6] A. Amin and R. Roberts. (2006). Communities of Practice? Varieties of Situated Learning [Online]. Available: http://www.dimeeu.org/files/active/0/Amin_Roberts.pdf.

[7] J. Lave and E. Wenger, Situated Learning: Legitimate Peripheral Participation. Cambridge, MA: Cambridge University Press, 1991.

[8] E. Wenger. (2006). Communities of Practice: A Brief Introduction [Online]. Available: http://www.ewenger.com/theory/.

[9] S. Guatelli et al., "Transferring advanced physics research tools to education: How to teach simulation tools used in radiation physics research to university students," in Proc. 4th Int. Technology, Education and Development Conf., Valencia, Spain, 2010, pp. 3546-3556.

[10] S. Guatelli et al., "The teaching/research nexus and internationalisation: An action research project in radiation physics," J. Univ. Teaching \& Learning Practice, vol. 7, no. 2, 2010.

[11] Centre For Medical Radiation Physics, University of Wollongong. (2012). Geant4 User Workshop [Online]. Available: http://www.uow.edu.au/eng/phys/cmrp/UOW091592.

[12] D. G. Wastall, "Learning dysfunctions in information systems development: overcoming the social defenses with transitional objects," MIS Quarterly, vol. 23, no. 4, pp. 581-600, 1999.

[13] D. F. Wood, "Problem based learning," British Medical J., vol. 326, no. 7384, pp. 328-330, Feb. 2003.

[14] The Root Team. (2012). ROOT: A Data Analysis Framework [Online]. Available: http://root.cern.ch/drupal/.

[15] H. S. Barrows and R. M. Tamblyn, Problem-Based Learning: An Approach to Medical Education. New York: Springer, 1980.

[16] X. Du et al., Eds., Research on PBL Practice in Engineering Education. Rotterdam, The Netherlands: Sense Publishers, 2009.

[17] S. Krishnan, "Student experiences of problem-based learning in engineering: Learning cultures of PBL teams," Ph.D. dissertation, Sch. Educ., Victoria Univ., Melbourne, Australia, 2009. 